
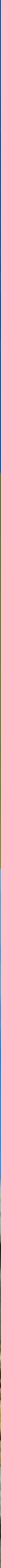


\section{Panta Rei \\ Revista Digital de Ciencia \\ y Didáctica de la Historia}

\section{6}

Revista anual

Fecha de inicio: 1995

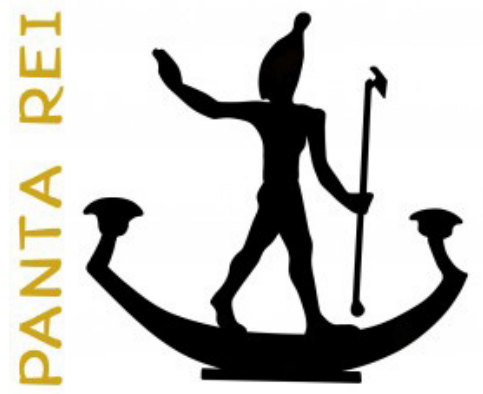

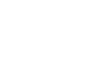




\section{CONSEJO DE REDACCIÓN}

\section{Coordinador editorial}

Egea Vivancos, Alejandro

[Didáctica de las Ciencias Sociales, UMU]

\section{Editores}

Botí Hernández, Juan Jesús

[CEPOAT, UMU]

Meseguer Gil, Antonio José

[CEPOAT, UNED]

Sáez Giménez, David Omar

[CEPOAT, UMU]

Sánchez Mondéjar, Celso Miguel

[CEPOAT, UMU]

\section{Secretaria}

Arias Ferrer, Laura

[Didáctica de las Ciencias Sociales, UMU]

\section{Responsable informático}

Martínez García, José Javier

[CEPOAT, UMU]

\section{Traducción y corrección lingüística}

Martínez Martínez, Cristina

[Sociedad Española de Lenguas Modernas]

Albaladejo Albaladejo, Sara

[ISEN, UMU]

\section{CONSEJO ASESOR}

Albero Muñoz, M. ${ }^{a}$ del Mar

[H. ${ }^{a}$ del Arte, UMU]

Chapman, Arthur

[History Education, UCL, Reino Unido]

Cobacho López, Ángel

[Derecho, UMU]

Egea Bruno, Pedro M. ${ }^{\text {a }}$

[Historia Contemporánea, UMU]

García Atienzar, Gabriel

[Prehistoria, UA]

González Monfort, Neus

[Didáctica de las Ciencias Sociales, UAB]

Haber Uriarte, María

[Prehistoria, UMU]

Hutson, Scott R.

[Anthropology, UK, EEUU]

Irigoyen López, Antonio

[Historia Moderna, UMU]

Mahony, Simon

[Digital Humanities, UCL, Reino Unido]

Marsilla de Pascual, Francisco Reyes

[Técnicas historiográficas, UMU]

Miralles Maldonado, José Carlos

[Filología Clásica, UMU]

Molina Gómez, José Antonio

[Historia Antigua, UMU]

Noguera Celdrán, José Miguel

[Arqueología, UMU]

Pérez Molina, Miguel Emilio

[Filología Clásica, UMU]

Prados Martínez, Fernando

[Arqueología, UA]

Sánchez Ibáñez, Raquel

[Didáctica de las Ciencias Sociales, UMU]

Sancho Gómez, Miguel Pablo

[Educación, UCAM]

Vilar García, María José

[Historia Contemporánea, UMU]

Zamora López, José Ángel

[Próximo Oriente Antiguo, CCHS-CSIC] 

Artículos

Los orígenes de la tecnología a debate: una revisión de las primeras industrias líticas.

Arturo Cueva Temprana.

De arqueología menorquina: Maria Lluïsa Serra Belabre y los círculos talayóticos de Sant Vicenç d' Alcaidús (Alaior, Menorca).

Octavio Torres Gomariz.

Nuevas cuestiones sobre el anfiteatro de Zaragoza.

José David Mendoza Álvarez.

Castidad o castigo. El estupro de las Vestales como símbolo de desorden social en Roma.

Juan Antonio Montalbán Carmona.

La Historia antigua en la Biblioteca de Focio.

Juan Luis Posadas Sánchez.

Usos sociales de la historia. La estrategia de Olga Cossettini, Rosario, 1935-1943.

Paula Caldo, Micaela Pellegrini Malpiedi y Agustina Mosso

Contribuciones a la didáctica de la Historia a través del método de análisis del objeto: como ejemplo... una "vasulla".

Nayra Llonch Molina y Verónica Parisi Moreno.

How are digital methods changing research in the study of the classical world? An EpiDoc case study. Katherine Steiner y Simon Mahony.

\section{Reseñas}

I Congreso Internacional "Creando ciudadanos, construyendo identidades. El uso del patrimonio material e inmaterial en la enseñanza de la historia."

José Díaz Serrano, Ainoa Escribano Miralles, Ana Isabel Ponce Gea y David Verdú González 151

Beckert, S. (2014). Empire of cotton: A global history. New York: Alfred A Knopf. 640 págs.

Ricky D. Mullins Jr..

Coumert, M. y Dumézil, B. (2013): Los reinos bárbaros en Occidente (traducción de Peinado Santaella, R. G.: Les royaumes barbares en Occident, Presses Universitaires de France, 2010). Editorial Universidad de Granada. Granada. 156 págs.

José Ángel Castillo Lozano.

La prehistoria en Las tres edades de Buster Keaton.

Alberto Lombo Montañés y Esther Rodríguez Ortiz.

Normas de publicación/Publishing rules 



\title{
La Historia antigua en la Biblioteca de Focio
}

\author{
Ancient History in the Bibliotheca of Photius
}

Juan Luis Posadas Sánchez 1

Universidad Antonio de Nebrija

Recibido: $21 / 04 / 2016$

Aceptado: 06/05/2016

Para citar este artículo: Posadas Sánchez, J. L. (2016). La Historia antigua en la Biblioteca de Focio. Panta Rei. Revista Digital de Ciencia y Didáctica de la Historia, 87-95.

ISSNe: 2386-8864

DOI: $10.6018 /$ pantarei/2016/5

\section{Resumen}

En este artículo analizamos las referencias a obras históricas en la Biblioteca de Focio, dos veces patriarca de Constantinopla, autor polígrafo del siglo IX de nuestra era. En nuestro análisis veremos cómo los gustos historiográficos de Focio -y por extensión de todos los estudiosos bizantinos de la época- se decantaban por las historias escritas de manera lineal, sin demasiados datos, con una narrativa fundamentalmente descriptiva. También conoceremos que en esa época se podían encontrar aún copias completas de autores como Diodoro de Sicilia. Focio se presenta así, como un autor de conocimiento inexcusable tanto para los historiadores de la Antigüedad, como para los interesados en la historiografía antigua.

\section{Palabras clave}

Historia de Europa, Historiografía, Literatura clásica, Autores, Cristianismo, Civilización griega.

\section{Abstract}

In this paper, we study the references to historical books present in the Bibliotheca of Photius, twice a Patriarch of Constantinople, and a prolific writer of the 9th Century. In our study, we shall see the historiographic interests of Photius, mainly the lineal writing with not too many facts in them and a descriptive narrative. We shall know that in his age, books already unknown for us were at disposal, at least in Constantinople. Photius is an author to be known and read for both, historians and people interested in writing of History.

\section{Key words}

European History, Historiography, Classical Literature, Authors, Christianity, Greek Civilization.

1 Para contactar con el autor: Juan Luis Posadas Sánchez. juanluposadas@hotmail.com. 


\section{Introducción}

Lo que conocemos de la Historia Antigua no se puede separar de la fortuna que corrieron las obras de los historiadores antiguos durante la Edad Media. La pérdida de muchas obras históricas (y de todo tipo) de la Antigüedad se debió no solo a las destrucciones e incendios de las bibliotecas del mundo antiguo -que también- sino a la necesidad imperiosa de transcribir las obras escritas en rollo de papiro - material muy frágil y poco duradero- a códices de pergamino -un soporte a más largo plazo-. El problema es que un códice de pergamino (al fin y al cabo, pieles de animales) era mucho más caro de producir que un rollo de papiro. Y la carestía de ese soporte llevó a que se tomaran decisiones muy discutibles en los siglos II-V en cuanto a las obras que debían ser copiadas y las que no; decisión que muchas veces se tomó basándose en la selección de unas pocas obras y autores que canónicamente debían ser leídas y estudiadas en la escuela primaria y secundaria (Cavallo, 1995; Sanz Morales, 2008).

El problema fundamental fue que se preservaron en las bibliotecas solo los códices transcritos, y los originales en rollo fueron desechados, si no destruidos (Casson, 2003). No hay duda que este primer momento de transcripción del rollo al códice ha de ponerse en relación con la fundación de un Scriptorium o taller de copia de libros asociado a la Biblioteca Imperial de Constantinopla ya en el año 357 por parte de Constancio II (Posadas, 2005) ${ }^{2}$, constituyendo el germen de la futura Biblioteca de la Universidad (Wilson, 1994).

A todo ello habría que añadir otro momento de crisis (siglos VIII-IX) en el que se transliteraron los pergaminos anteriores escritos en letras unciales (mayúsculas) a letras minúsculas, debido a que este tipo de letra ocupaba mucho menos espacio en el caro pergamino, y permitía además una escritura mucho más rápida. Debemos la supervivencia de casi toda la literatura antigua a las copias en minúscula del siglo IX (Reynolds-Wilson, 1986). La mayoría de las copias en minúscula en Bizancio fueron realizadas a petición de la Universidad de Constantinopla y conservadas en la biblioteca de dicha institución, o en la del patriarca (Reynolds-Wilson, 1986). Ello ha sido puesto en relación con la cada vez mayor importancia de la Universidad de Constantinopla a partir del siglo IX, y su énfasis en textos no solo religiosos sino también profanos (Dain, 1954). Pero muchas pérdidas se debieron al poco interés bizantino en la historia helenística o en las historias locales (Kaldellis, 2012).

Es muy interesante, por lo que está pasando actualmente con la transcripción de los libros en papel a formatos electrónicos de futuro incierto, pararse a descubrir los diferentes momentos por los que esta transmisión de la historiografía antigua fue pasando, para intentar descubrir la causa de que algunos historiadores pervivieran y otros no.

En esa historia de la historiografía antigua, Bizancio desempeñó un papel crucial, al ser dicha civilización la heredera directa y sin cesura del Imperio romano oriental. La conservación de muchas obras del mundo antiguo quedó asegurada por varios hechos ocurridos entre finales del siglo IV y comienzos del VI. En concreto, estos hechos (o posibles hechos) fueron: el traslado de parte de la Biblioteca del Museo de Alejandría a Constantinopla antes de su destrucción en el año 391 (Escolar, 2001), la fundación de la Universidad Imperial de Constantinopla por parte de Teodosio II en el año 425 (Cod. Theod. VI.21.1 y XIV.9.3) (Posadas, 2005), y el cierre y traslado de obras de las academias y centros de estudios paganos decretado por Justiniano en el año 529 (Blumenthal, 1978; Fernández, 1985) ${ }^{3}$. En ese siglo y medio que media entre la destrucción del Museo de Alejandría en 391 y el cierre de la Academia de Atenas en 529, vemos cómo Constantinopla se convierte en el mayor centro del saber antiguo, a cuya Universidad confluyeron libros -si no bibliotecas enteras- de centros académicos paganos como Alejandría o Atenas (Casson, 2003).

En la Biblioteca de la Universidad de Constantinopla, o en la patriarcal, pudo formarse el autor

2 Aunque lo conocemos por una Constitución posterior, del año 372, debida a Valente (Cavallo, 1995, p. 127).

3 Por más que este autor, pp. 24-30, defiende que dicha institución siguió en funcionamiento al menos hasta el siglo VII. 
de la Biblioteca, el gran humanista bizantino y dos veces patriarca de Constantinopla Focio (aprox. 810-890). Focio vivió en una época en que triunfó el culto a las imágenes sobre la iconoclasia anterior, que había llegado hasta la destrucción de los libros que contradecían esa doctrina. De hecho, Focio consideró a su propia época como propicia para la lectura y el estudio de autores antiguos y contemporáneos (Treatgold, 1978). Su Biblioteca figura como el primer momento de la revalorización de la historiografía antigua o clásica, junto con el renacimiento vivido un siglo después bajo el reinado de Constantino VII Porfirogéneto (Kaldellis, 2012).

\section{El autor y la obra}

No sabemos ni el año ni el lugar de nacimiento de Focio, asuntos sobre los que los eruditos no se han puesto de acuerdo, pero podríamos resumir dicho debate en que nació en Constantinopla en torno al año 810 (Ahrweiler, 1965). Tampoco sabemos el nombre de su padre, aunque podría ser un profesor de la Universidad de nombre Sergio (Cf. Nogara, 1978). El nombre de su madre era Irene. Su tío materno estaba casado con una de las hermanas de Teodora, la emperatriz esposa de Teófilo. Además, uno de sus tíos paternos fue el patriarca Tarasio (784-806), un defensor del culto a las imágenes ${ }^{4}$. Por todos estos vínculos, cabe considerar a Focio miembro de la aristocracia palatina bizantina. Como miembros de esa aristocracia, el hermano mayor de Focio, Tarasio, disfrutó de la condición de Patricio.

Durante sus primeros años, sabemos por el testimonio de Nicetas David en su Vida del Patriarca Ignacio, que tomó la costumbre de leer todo lo que pudo de todas las facetas del conocimiento, incluida la medicina, dedicando muchas noches sin dormir a dicha tarea (Smithies, 2013). También leyó mucho sobre Teología, como atestigua el hecho de que el $43 \%$ de las obras descritas en su Biblioteca sean religiosas (incluyendo obras judías y "heréticas") frente al $57 \%$ de obras laicas o paganas (Treatgold, 1980). Esta doble filiación temática quizá tenga que ver con las dos Bibliotecas que pudo haber consultado Focio en la capital del Imperio: la universitaria y la patriarcal.

Entre los años 832 y 842, durante la persecución iconoclasta habida en los últimos diez años de reinado del emperador Teófilo, y pese a ser familiares de la emperatriz, Focio y su familia fueron enviados al exilio, en el que sus padres murieron. La muerte del emperador supuso la subida al poder como regente de la pariente de Focio, la emperatriz Teodora, por lo que todos volvieron a Constantinopla. Al parecer, Focio comenzó a enseñar (aunque no hay ninguna prueba de ello según Lemerle, 1990), y también a ascender en la corte, en la que llegó a ostentar del cargo de Protoasekrétis (jefe de la cancillería imperial, según Oikonomidès, 1972), posiblemente hacia el año 845 (Treatgold, 1980). Hay que destacar que este cargo fue el paso previo al patriarcado también en los casos de su tío Tarasio y de Nicéforo (Lemerle, 1990).

Como alto cargo de la corte, Focio residía en Constantinopla pero también tuvo algunas "misiones" exteriores, como la famosa embajada "a los asirios" (es decir, a Siria o a Bagdad) que aparece citada en el Prefacio de la Biblioteca como razón para escribir dicha obra para su hermano Tarasio (Hägg-Treatgold, 1986). Esa sería la fecha probable de la escritura de la obra, que Treatgold, basándose en otros autores como Ziegler o Hergenröther, sitúa en el año 845 (Treatgold, 1980) ${ }^{5}$. Ello sin descartar -por evidencias mostradas en los últimos años- que la obra fuera reescrita o al menos aumentada durante los dos periodos en que Focio desempeñó su famosísimo patriarcado cismático $(858-867 \text { y } 877-886)^{6}$.

4 Focio le llama patrótheios o "tío del padre" en sus Cartas 3, 4 y 5.

5 Aunque Wilson (1994, p. 139), data dicha embajada durante el periodo de ausencia de Focio por su exilio, hacia el año 838. Desde nuestro punto de vista, es muy difícil que, con 28 años de edad, Focio hubiera podido leer ya casi 300 libros, alguno de ellos con muchos volúmenes.

6 Por ejemplo, se han señalado evidencias de obras que están en la Biblioteca pero que no fueron publicadas hasta el año 876, por lo que debieron ser añadidas con posterioridad al envío de la Biblioteca a Tarasio en el 845 (Maraglino, 2007). Otro autor (Ronconi, 2013), cree que la referencia a la embajada a los asirios alude a 
La Biblioteca o Myriobiblion no es el título original de esta obra, sino nombres que se le dieron a partir del siglo XVI. Su título original es muy largo: Inventario y enumeración de los libros que he leído, o de los cuales nuestro querido hermano Tarasio me pidió un análisis general. Aquí nos referiremos a ella como Biblioteca. En realidad, no es ni un inventario ni una Biblioteca, sino una colección de reseñas bibliográficas, género "inventado virtualmente por el propio Focio" (Wilson, 1994). Focio dice que los libros que él ha leído son 279 , pero en realidad son 280 , incluyendo un códice, el 268, que dice expresamente que no ha leído. Todas las reseñas comienzan con el verbo Anegnósthe, seguido por el título del libro. Los comentaristas han numerado cada lectura y las han descrito como "códices", aunque algunos de ellos describen más de un volumen manuscrito, o incluso contienen más de una obra (Bevegni, 1996).

Es importante aludir a una polémica existente sobre la forma de trabajar de Focio. Algunos autores defienden que Focio escribió "de memoria" su obra, con una capacidad de retentiva increíble, pues estamos hablando de un libro de 1600 páginas con 300 referencias bibliográficas, pero que se ayudó de notas tomadas durante sus lecturas (Wilson, 1968, p. 454; Hägg, 1973). Otros autores creen que algunas obras las reseñó de memoria, otras las tenía delante de sus ojos cuando las comentó, y otras las reseñó con diccionarios biográficos como el Epítome de Hesiquio o la fuente de la posterior Suda (Treatgold, 1980; Schamp, 1987).

En la Biblioteca hay casi de todo, leído muchas veces al azar y sin orden ni concierto (Nogara, 1975). Sin embargo, están explícitamente excluidas las obras de lectura obligatoria en la escuela, con lo que mucha filosofía, poesía o retórica no aparecen en ella (Treatgold, 1980). Este mismo autor describe muy acertadamente el tipo de obras que aparecen en la Biblioteca y las divide entre obras laicas o seculares y obras religiosas, predominando las primeras. Entre ellas hay obras de diferentes temas: historia (que es el objetivo de este artículo), oratoria, ficción en prosa, medicina, mitología, biografía, epistolografía, paradoxografía, filosofía y ciencias. Sin embargo, de todos los textos laicos o seculares, los históricos son los más numerosos (Reynolds-Wilson, 1986).

\section{La Historia antigua en la Biblioteca}

"No debe olvidarse que los textos históricos ocupan un lugar de privilegio en la Biblioteca" (Wilson, 1994, p. 141). Este mismo autor opina que Focio fue un lector "omnívoro", lo cual explica tanto el interés que tiene en autores poco importantes o anecdóticos como Memnón, cuanto su preferencia por estilos sencillos y poco complicados, con poco detalle (Wilson, 1994). Hay que decir que la Historia normalmente es descrita con mayor extensión que otros temas. Una primera selección hecha por Focio -aparte de la obvia de la disponibilidad de esos libros en su época- fue su preferencia por la narrativa histórica clara y de fácil lectura.

Hay en la Biblioteca 37 títulos de Historia o Biografía, si bien entre ellos están las compilaciones en varios volúmenes de Apiano, Dión Casio, Diodoro Sículo y Dionisio de Halicarnaso, cuyos textos parece haber leído Focio en su totalidad (aunque con reservas en el caso de Diodoro, pues creemos que lo que leyó Focio fue un resumen posterior). Dejando de lado los historiadores de época ya bizantina temprana, hay veinte historiadores de la Antigüedad (hasta comienzos del siglo $\mathrm{V}$ ) en la Biblioteca de Focio. Son, por orden cronológico:

1. Heródoto, siglo V a. C.

2. Agatárquidas de Cnido, siglo II a. C.

3. Dionisio de Halicarnaso, siglo I a. C.

4. Diodoro Sículo, siglo I.

5. Flavio Josefo, siglo I.

6. Justo de Tiberíades, siglo I.

un pasaje bíblico y tiene relación con el primer exilio de Focio como patriarca, hacia el año 870 . A ello hay que añadir que ya hubo autores anteriores que mostraron que algunos códices no habían sido publicados sino hasta los años setenta del siglo IX (Halkin, 1963). 
7. Memnón, siglo I.

8. Apiano, siglo II.

9. Arriano, siglo II.

10. Cefalión, siglo II.

11. Plutarco, siglo II.

12. Julio Africano, siglos II-III.

13. Dexipo, siglo III.

14. Dión Casio, siglo III.

15. Herodiano de Siria, siglo III.

16. Eusebio de Cesarea, siglos III-IV.

17. Praxágoras de Atenas, siglo IV.

18. Teopompo de Quíos, siglo V.

19. Eunapio de Sardes, siglos V.

20. Olimpiodoro de Tebas, siglo V.

Empecemos a reseñar brevemente lo que dice de estos historiadores.

De Heródoto, autor de Nueve libros de la Historia, del siglo V a. C., dice en el códice 60 que es el modelo del dialecto Jónico, de la misma manera que Tucídides lo es del Ático. De él dice que su historia contiene muchas fábulas y digresiones, pero que no oscurecen su estilo, sino que lo dulcifican. Sin embargo, Focio solo da noticias de lo acontecido con relación a Jerjes, Cambises y Darío como reyes de Persia, por lo que no parece que leyera la obra completa (dado que no proporciona detalles sobre otros hechos que aparecen en ella). Termina su reseña con una anécdota apócrifa sobre Tucídides (que lloró cuando oyó una lectura pública de Heródoto), recogida, al parecer, en la Vida de Tucídides de Marcelino (Wilson, 2002).

De Agatárquidas de Cnido, autor del siglo II a. C., nos deja dos códices, el 213 y el 250 . En ellos recoge noticias sobre su Mar Rojo o de Eritrea, así como de otras de sus obras perdidas (Marcotte, 2001). De él dice que domina el estilo ático y que proporciona muchos detalles sobre la historia y geografía de esos lugares (de interés para los bizantinos del siglo IX), con una fascinación por los personajes fantásticos que describe, si bien critica su falta de claridad y el exceso de detalles que la hacía aburrida. Aun así, Focio parece respetar los datos geográficos y etnográficos que transmite Agatárquidas (Sánchez León, 1981-1985).

En los códices 83 y 84 nos da Focio noticias sobre las Antigüedades romanas (además de un resumen de dicha obra), de Dionisio de Halicarnaso, del siglo I a. C. De Dionisio nos dice que «su estilo y dicción están marcados por la innovación, lo cual impulsa a la narración fuera de lo trillado, pero su interés por los detalles producen una cierta simplicidad en los sentimientos [...] su interés por las digresiones alivian al lector y le previenen del aburrimiento por la historia, le refrescan y le reviven» (Códice 83.65a). Más interesante es lo que nos dice en el códice 84: data el resumen hacia el siglo III d. C., y parece preferir dicha sinopsis a la obra original, lo cual es muy indicativo del poco interés bizantino por la historia romana: «en este, su estilo es más elegante pero no más agradable; al mismo tiempo, la obra es más útil, ya que nada se ha insertado en ella que no sea absolutamente necesario» (Cód. 84.65a).

De Diodoro Sículo y su Biblioteca de Historia, del siglo I d. C., nos transmite noticias en dos códices, el 70 y el 244. Las opiniones de Focio sobre este autor son elevadas, alabando su estilo como «claro, sin adornos y admirablemente adaptado para la historia». También considera creíbles sus datos sobre hombres con características físicas de mujer. Sin embargo, la brevedad de ambas reseñas, comparada con el volumen de la obra (cuarenta libros), parecen indicar que Focio no se leyó completamente todos los volúmenes, sino solo las partes dedicadas a Julio César, a quien menciona en dos ocasiones en la breve reseña del códice 70.

Flavio Josefo, el historiador judío del siglo I d. C., está muy presente en la Biblioteca de Focio, en tres códices: el 47, el 76 y el 238. En el códice 47, Focio reseña las Antigüedades Judías, que considera de alto interés y buen estilo, y se para a relatar algunas anécdotas del asedio de Jerusalén por los romanos. En el códice 76 reseña otra vez las Antigüedades y también algo sobre 
su Autobiografía. Este códice ha llamado la atención de Maas por las palabras que dedica en extenso al cargo de Sumo Sacerdote de Jerusalén, que el autor cree tienen que ver con el patriarcado y, por tanto, podrían servir para datar la Biblioteca en el año 870 (Maas, 1990).

De la Crónica de los reyes Judíos del casi desconocido Justo de Tiberíades, del siglo I d.C, autor enemigo de Flavio Josefo, nos transmite noticias en el códice 33. En esta reseña encontramos algún comentario que hoy denominaríamos "xenófobo" contra los judíos, pues dice expresamente que Justo «sufre del fallo común de los judíos, a cuya raza pertenece, ya que no menciona ni la venida de Cristo, ni los acontecimientos de su vida, ni los milagros realizados por Él» (Cód. 33.6b).

La Historia de Heraclea Póntica de Memnón, un autor del siglo I d. C., es el único ejemplo de historia local del que se conserva algo; y ello a pesar del poco interés de los bizantinos por los localismos (Kaldellis, 2012). Todo lo que sabemos de esta obra proviene del resumen realizado por Focio, aunque este nos dice que en su época solo se conservaba ya la mitad de la obra, en concreto los libros IX al XV. Otra vez encontramos en el texto de Focio una alabanza del estilo llano y sin florituras ni digresiones innecesarias.

Focio nos deja un comentario también sobre una obra que conocemos parcialmente: la Historia romana de Apiano. En la época de Focio todavía se conservaba íntegramente, por lo que la Biblioteca se convierte en una fuente inestimable para valorar la obra completa de este autor. Aun así, Focio parece dedicar más espacio y tiempo a la parte conservada hoy que es la de las guerras civiles, al parecer de una manera reelaborada pues no concuerda totalmente con lo que se nos ha conservado (Amerio, 2006). El comentario de Focio termina con una breve biografía, de las que al parecer extrajo de un Epítome o resumen existente en su época de la obra perdida Onomatologus de Hesiquio de Mileto (Treatgold, 1980).

Para Focio, la Historia debía ser de fácil lectura. Así se entiende la alabanza hecha a Arriano: «Este autor no es inferior a ninguno de los mejores historiadores. Es excelente en su narrativa concisa y nunca compromete la continuidad de su narración con digresiones o añadidos a destiempo. Innova más en la sintaxis que en el vocabulario, pero lo hace de tal manera que su narración no podría ser más clara y vívida utilizando otro recurso» (Cód. 92.73a). De hecho, Focio es el único autor que nos transmite referencias completas sobre las obras perdidas de Arriano (Coppola, 1981). En el códice 58, sobre las Párticas, nos da una relación extensa de las obras de Arriano, prácticamente todas perdidas. En ese códice, sin embargo, nos dice que «su estilo es seco y es un genuino imitador de Jenofonte». En el códice 91 nos transmite la Historia del reino de Alejandro de Arriano, otra de sus obras perdidas, seguida por el relato de su obra "sobre lo que sucedió tras la muerte de Alejandro" en diez libros, en el códice 92, con importantísimas referencias históricas que, de no ser por él, se hubieran perdido (estudiadas en profundidad en la Tesina de McGilvery, 2014). Finalizando con este autor, el códice 93 nos transmite algunos detalles sobre sus Bitínicas («una obra de su propio país»).

Focio en su códice 68 repasa la Historia de Asiria en nueve libros (llamados como las Musas), del historiador romano del siglo II Cefalión. Focio parece criticar de esta obra dos cosas: que el autor no dice nada de sí mismo salvo que la escribió durante su exilio en Sicilia, lo cual le parece algo indicativo de su poco carácter (quizá debido a que el propio Focio estuvo exiliado sin aludir nunca a ello); y que cita muchísimas fuentes (más de 500 para su primer libro), pero pocos autores, lo cual le parece a Focio de poco crédito.

El siguiente autor por orden cronológico es Plutarco, de cuyas Vidas paralelas Focio solo reseña algunas. Lo cual no significa que no leyera todas (Treatgold, 1980). Es importante decir que Focio solo habla de Vidas que se han conservado en nuestra época, por lo que es evidente que las que no se conservan se habían perdido ya en el siglo IX. También es interesante señalar que algunas conjeturas y lecturas que hace Focio son muy fieles al texto original de Plutarco, como ha demostrado el estudio de los manuscritos existentes (Schamp, 1982).

Del autor cristiano del siglo III Julio Africano y su Historia nos ha dejado Focio un breve comentario en su códice 34. Focio alaba en Julio su estilo conciso y que no deja nada importante por contar, algo muy del gusto del lector bizantino de la época. Es interesante constatar que las 
cronologías de Julio Africano cuadran muy bien con el interés de Focio por la sucesión de imperios en Oriente (Mendels, 1986, p. 197). Focio es, además, la fuente que nos indica que Julio Africano escribió otras obras, como los Celti o algunas cartas apologéticas.

En cuanto a Dexipo, autor del siglo III, Focio nos transmite noticias de tres de sus libros en sus códices 82-83: Historia después de Alejandro, Breve Historia y sus Escíticas (realmente un libro sobre los godos). De él dice, literalmente, que "su estilo está libre de redundancias, es masivo y digno. Debería ser llamado un "segundo Tucídides", aunque él escribe de forma más clara» (Cód. 82.64a). Estas opiniones distan mucho de ser ciertas, al menos según los fragmentos de Dexipo conservados.

Focio también leyó la Historia de Dión Casio, aunque es improbable que lo hiciera en sus ochenta libros originales, sino solo la parte correspondiente a la vida de Alejandro Severo, que es lo único que comenta en el códice 71. Al parecer, sí que pudo leer también algún dato autobiográfico del autor en una parte de su obra perdida para nosotros (Treatgold, 1980).

El códice 99 está dedicado a la Historia de Herodiano de Siria, un autor también del siglo III, que se nos ha conservado prácticamente al completo. De él dice que «no se detiene en lo superfluo, pero tampoco omite nada necesario; en una palabra, pocos hay superiores a él en las buenas cualidades como historiador» (Cód. 99.84b).

Uno de los autores más citados por Focio, en nada más y nada menos que nueve códices, es el cristiano Eusebio de Cesarea, del siglo IV. Sin embargo, la mayoría de las obras leídas por Focio corresponden a su apologética o a su Historia eclesiástica, y no a sus obras más históricas. Sin embargo, sí reseña un Encomio del emperador Constantino el Grande, autoría que algunos discuten hoy (Wilson, 1994). Focio elogia el estilo de Eusebio, aunque critica algunos cambios en las palabras para obtener más efecto. Sin embargo, a Focio lo que más le llama la atención es cómo Eusebio evita pronunciarse sobre las opiniones de Arrio, lo cual le induce a pensar que este autor podía ser herético.

Focio dedica su códice 62 a la Historia de Constantino el Grande de Praxágoras de Atenas, un autor pagano del siglo IV. Lo primero que hay que señalar es el interés de Focio por este emperador, sobre quien también leyó otras obras, entre ellas la anteriormente mencionada de Eusebio. Algo natural para un constantinopolitano: de hecho, en este códice menciona que Constantino fundó "Bizancio" (como Focio llama a su propia ciudad).

Focio también tuvo interés en leer a Teopompo de Quíos, un historiador de comienzos del siglo V, que escribió unas Filípicas, o historia de Filipo de Macedonia. Focio detalla que ya desde hacía tiempo se habían perdido cuatro de sus treinta y tres libros, y que él no había podido encontrarlos, lo cual es indicativo de cuánto había perdido la literatura antigua en los menos de cuatro siglos transcurridos entre las épocas de Teopompo y de Focio. Esta reseña es interesante porque recoge con cierta profusión, detalles de la vida de Teopompo, alguno de ellos -como que él y Éforo fueron pupilos de Isócrates- absolutamente ciertos y claros, tanto por el testimonio de Focio como por la semejanza entre ambos autores (Ottone, 2013).

Eunapio de Sardes escribió una continuación de la Crónica de Dexipo en catorce libros, comprendiendo desde la época del emperador Claudio hasta la de Arcadio, hijo de Teodosio. Focio ataca duramente a este Eunapio por haber criticado a Constantino el Grande y alabado a Juliano el Apóstata, lo cual es hasta cierto punto lógico en un autor cristiano que llegó a patriarca. Sin embargo, no es excesivamente crítico con él como historiador.

Finalizamos esta relación de historiadores de la Antigüedad (hasta comienzos del siglo V) con Olimpiodoro de Tebas, autor de una Historia del Imperio romano, de la que sabemos algo sobre todo por Focio, pero también por Filostorgio y por Sozomeno (Wilson, 2002). Esta obra en veintidós libros abarcaba básicamente la segunda mitad del reinado de Honorio desde el año 407 hasta su muerte en el 423. Focio parece haber leído realmente la obra de Olimpiodoro, dada la extensión de su resumen. La opinión que tiene de este autor no es buena, y de hecho dice que su obra «no merece ser clasificada como Historia» (Cód. 80.56b). También critica su falta de estilo, la sequedad del mismo, y el hecho de dividir de manera artificial su obra en libros, aumentando su extensión 
con prefacios y profusas dedicatorias al emperador Teodosio II. Esta manera de escribir Historia es típica de una época decadente como fue el siglo V (Stickler, 2014, p. 101).

\section{Reflexiones finales}

La Biblioteca de Focio es uno de esos libros que todos consideran "obra cumbre de la Bizantinística" pero que, debido a la ausencia de ediciones completas y traducciones, pocos conocen mínimamente y, muchos menos, han leído aunque sea parcialmente. Pero es una obra fundamental para conocer una parte importante de la cultura antigua desaparecida en nuestros días. De hecho, de las 279 obras reseñadas por Focio, 211 no se conservan completamente hoy día (un $76 \%$ ). Es más, para 81 obras (un 29\%), la Biblioteca es la única fuente de que alguna vez existieron. Solo estos datos justificarían una edición y/o traducción completa de la gran obra de Focio.

Como historiadores de la Antigüedad, Focio es una fuente inestimable de conocimientos: tanto para escribir una historia de la Historiografía antigua (que es nuestro mayor interés) como para documentar numerosísimos episodios de la historia comprendida entre la época de Heródoto y la de Olimpiodoro (unos mil años).

En concreto, hemos encontrado referencias a 20 historiadores de la Antigüedad tan conocidos como Heródoto, Dionisio de Halicarnaso, Diodoro Sículo, Flavio Josefo, Apiano, Arriano, Plutarco, Herodiano o Eusebio. Pero también a otros tan olvidados como Memnón, Cefalión o Dexipo. Un estudio en mayor profundidad de estos autores y obras a través de Focio se nos antoja ineludible.

\section{Bibliografía}

Amerio, M. L. (2006). Appiano in Fozio. Quaderni di Storia 32, 303-309.

Ahrweiler, H. (1965). Sur la carrière de Photius avant son patriarcat. Byzantinische Zeitschrift 58, 348-363.

Bevegni, C. (1996). La Biblioteca di Fozio e la sua origine. Humanitas: Rivista Bimestrale di Cultura 51, 326-347.

Blumenthal, H. J. (1978). 529 and after: What happeneed to the Academy?, Byzantion: Revue Internationale des Études Byzantines 8, 369-385.

Casson, L. (2003). Las bibliotecas del mundo antiguo. Barcelona: Bellaterra.

Cavallo, G. (1995). Libros, editores y público en el mundo antiguo. Madrid: Alianza Editorial.

Coppola, C. (1981). L'Historia Romana di Appiano e i Parthica di Arriano nella Biblioteca di Fozio. En

I. Gallo (Dir.), Studi salernitani in memoria di R. Cantarella (pp. 475-491). Salerno: Universitá di Salerno.

Dain, A. (1954). La transmission des textes littéraires classiques de Photius à Constantin Porphyrogénète. Dumbarton Oaks Papers 8, 33-47.

Escolar, H. (2001). La Biblioteca de Alejandría. Madrid: Gredos.

Fernández, G. (1983). Justiniano y la clausura de la escuela de Atenas. Erytheia, 2, 24-30.

Hägg, T. (1973). Photius at work. Evidence from the text of the Bibliotheca. Greek, Roman and Byzantine Studies 14, 213-222.

Hägg, Th. - Treadgold, W. (1986). The preface of the Bibliotheca of Photius once more. Symbolae Osloenses: Norwegian Journal of Greek and Latin Studies 61, 133-138.

Halkin, F. (1963). La date de composition de la Bibliothèque de Photius remise en question. Analecta Bollandiana: Revue Critique d'Hagiographie 81, 414-417.

Kaldellis, A. (2012). The Byzantine role in the making of the corpus of classical historiography: a preliminary investigation. Journal of Hellenic Studies 132, 71-85.

Lemerle, P. (1990). Libri, studi e scelte di lettura di un dotto bizantino: Fozio. En G. Cavallo (Ed.), Libri e lettori nel mondo bizantino. Guida storica e critica. Roma-Bari: Laterza, 65-84.

Maas, M. (1990). Photius' treatment of Josephus and the high priesthood. Byzantion 60, 183-194. 
Maraglino, V. (2007). Reconsidering the date of Photius' "Bibliotheca»: the biographical tradition of Gregory the Great in chapter 252. Ancient Society 37, 265-278.

McGilvery, P. (2014). Arrian's Events After Alexander in Photius. Halifax: Dalhousie Univ.

Mendels D. (1986). Greek and Roman history in the Bibliotheca of Photius. A note. Byzantion 56, 196-206.

Nogara, A. (1978). Sergio il confessore e il cod. 67 della Biblioteca di Fozio patriarca di Costantinopoli. Aevum 52, 261-266.

--- (1975). Note sulla composizione e la struttura della Biblioteca di Fozio, Patriarca di Costantinopoli. Aevum 49, 213-242.

Oikonomidès, N. (1972). Les Listes de préséance byzantines des Ixe et Xe siècles. París: CNRS.

Ottone, G. (2013). «In corsa nello stadio della storia»: Eforo e Teopompo secondo Fozio. Parola del Passato: Rivista di Studi Antichi 68, 241-288.

Posadas, J. L. (2005). Raíces tardo romanas de la Universidad europea: la Universidad Imperial de Constantinopla. En G. Bravo Castañeda - R. González Salinero (Eds.), La aportación romana a la formación de Europa: naciones, lenguas y culturas (207-214). Madrid: Signifer.

Reynolds, L. D. - Wilson, N. G. (1986). Copistas y filólogos. Las vías de transmisión de las literaturas griega y latina. Madrid: Gredos.

Ronconi, F. (2013). The Patriarch and the Assyrians: new evidence for the date of Photios' «Library». Segno e testo: International Journal of Manuscripts and Text Transmission 11, 387-395.

Sánchez León, M. L. (1981-1985). En torno a la transmisión de la obra de Agatárquides. Hispania Antiqua 11-12, 183-195.

Sanz Morales, M. (2008). La literatura griega: períodos y géneros. En P. Hualde Pascual - M. Sanz Morales (Eds.). La literatura griega y su tradición (7-21). Madrid: Akal.

Schamp, J. (1987). Photios historien des lettres. La Bibliothèque et ses notices biographiques. Paris: Les Belles Lettres.

--- (1982). A propós du Plutarque de Photios. Revue des Études Grecques 95, 440-452.

Smithies, A. (2013). Nicetas David: The life of Patriarch Ignatius. Washington: Dumbarton Oaks Studies.

Stickler, T. (2014). Das Geschichtswerk des Olympiodor von Theben. En B. Bleckmann - T. Stickler (Eds.), Griechische Profanhistoriker des fünften nachchristlichen Jahrhunderts (85-102). Stuttgart: Steiner.

Treatgold, W. T. (1980). The nature of the Bibliotheca of Photius. Washington: Dumbarton Oak Studies Studies.

--- (1978). Photius on the transmission of texts (Bibliotheca, Codex 187). Greek, Roman and Byzantine Studies 19, 171-175.

Wilson, N. G. (1994). Filólogos bizantinos. Madrid: Alianza Editorial.

--- (1968). The composition of Photius' Bibliotheca. Greek, Roman and Byzantine Studies 9, 451455.

\section{Fuentes}

The Library of Photius. Londres: MacMillan, vol. I. 1920 (traducción de J. H. Freese).

Photius: the Bibliotheca. Londres: Duckworth. 2002 (selección y traducción de N. G. Wilson). 


\section{Panta Rei}

PANTA REI es una revista digital de investigación orientada a la Historia y otras ciencias afines. Su principal objetivo es la transmisión del conocimiento científico, dando una oportunidad también a los jóvenes investigadores que quieren abrirse camino en el estudio de las ciencias humanas y sociales. Se compone de estudios originales relacionados con la disciplina histórica así como su didáctica y difusión. Las diferentes secciones que componen la revista son: artículos de investigación, entrevistas a profesionales, recensiones de monografías de actualidad y crónicas de congresos o eventos científicos relevantes.

Todos los artículos publicados son objeto de un proceso de revisión a cargo de un mínimo de dos evaluadores, que se consideran expertos en el ámbito temático del artículo propuesto. Nuestro deseo es poder ofrecer unos contenidos rigurosos, de calidad y de interés.

EI CEPOAT (Centro de Estudios del Próximo Oriente y la Antigüedad Tardía de la Universidad de Murcia) es la institución encargada de la coordinación y gestión de la revista, desde donde anualmente se lanzará la convocatoria para aquellos que estén interesados en publicar sus trabajos, siempre relacionados con la Historia, Arqueología, Historia del Arte, Didáctica de las Ciencias Sociales, etc.

PANTA REI is a digital journal focused on History and other sciences related to it. Its main objective is the transmission of scientific knowledge by giving also an opportunity to young researchers who want to make their way in the study of human and social sciences. It is composed by original studies related to History, as well as its didactics and promotion. The different sections of this journal are: research articles, interviews to professionals, recensions on monographs about current issues and reports about congresses or relevant scientific events.

All the articles published are subject to a revision process carried out by a minimum of two reviewers who are considered to be experts in the field of the article proposed. Our wish is to offer rigorous contents with quality and being of interest to the reader.

CEPOAT (Centre of Studies of the Middle East and Late Antiquity of the University of Murcia) is the institution in charge of the coordination and management of this journal. This is the centre from where the call for papers will be launched for all the people interested in publishing their papers, always related to History, Archeology, Art History, Didactics of the Social Sciences, etc. 


\section{Normas de Publicación}

El autor se compromete a enviar trabajos originales, que no se encuentren publicados en otras revistas ni en otros idiomas. Así mismo, el mismo artículo no podrá ser presentado en otras revistas mientras dure el proceso de evaluación.

\section{Envío y presentación de originales}

Los artículos se enviarán exclusivamente a través del correo electrónico a la dirección pantarei@um.es. Los textos serán enviados en formato DOC y las imágenes en formato JPEG o TIFF, y con un tamaño mínimo de 2000 px. Éstas no aparecerán incorporadas en el texto, sino enviadas en archivo aparte y correctamente numeradas según su posición en el texto. Junto al trabajo, se rellenará y enviará un documento aparte en el que se especifiquen los datos del autor siguiendo el modelo disponible en la página Web de la revista.

Para la redacción de los trabajos se tendrá en cuenta el Manual de la American Psychological Association, en su sexta edición. La extensión máxima de los trabajos será de 30 páginas. La tipografía será Arial 11, con interlineado sencillo y sin espacio alguno entre párrafos. El texto deberá ir justificado a ambos márgenes y sin sangría en los primeros párrafos. Los márgenes serán de $2,50 \mathrm{~cm}$. En los casos en los que fuera necesario incorporar notas, éstas irán a pie de página, enumeradas consecutivamente, con tipografía Arial 10, interlineado sencillo y justificadas a ambos márgenes.

Una información más detallada se encuentra disponible en la página http://www.um.es/cepoat/ pantarei.

\section{Proceso de valoración y evaluación}

Una vez recibidos los trabajos, la Revista realizará una primera valoración. Si el trabajo enviado se ajusta a las normas de presentación propuestas, la temática es coincidente con la línea editorial de la revista y posee la calidad científica necesaria, será remitido al consejo asesor para una primera evaluación. Si no es así en este primer paso se puede rechazar directamente los documentos que incumplan claramente la línea editorial.

Será el Consejo Asesor quien indique a la revista la originalidad, relevancia, estructura, redacción, aparato bibliográfico, etc. del trabajo enviado y, para ello, se designará a dos revisores expertos externos que evaluarán cada uno de los trabajos, que pueden formar parte (o no) de este Consejo Asesor. La selección de los revisores se ajustará a la temática y características metodológicas del trabajo. El nombre y filiación de los autores serán eliminados del trabajo para su revisión, así como los revisores actuarán de manera anónima y confidencial.

Los revisores deberán rellenar un informe de evaluación que centrará su atención en aspectos tales como características formales, originalidad y novedad de los trabajos, relevancia de las propuestas y los resultados, calidad metodológica y validez científica.

Una vez terminado el proceso se decidirá la aceptación o no de los mismos y su publicación en el número que sea pertinente, así como las modificaciones susceptibles de ser realizadas para su final publicación. Dicha notificación se enviará únicamente por correo electrónico, en un plazo máximo de seis meses. 


\section{Publishing rules}

The author is committed to submit original papers not having been published in other reviews or in other languages. In this way, it is not allowed for the same paper to be presented in other reviews during the evaluation process.

\section{Submission and presentation of originals}

The articles will be exclusively submitted by email to pantarei@um.es. The texts will be submitted in DOC format and the images in JPEG or TIFF format, and with a minimum size of 2000 px. Images will not be integrated in the text but sent in another file and properly numbered according to their position in the text. Attached to the paper, a document will be filled out and sent where the author's data will be specified following the model available on the website.

The sixth edition of the Manual of the American Psychological Association will be taken into account for the writing of the papers. The length of the papers must not exceed 30 pages. Typography will be Arial 11 , with simple line spacing and no space between paragraphs. The text must be justified on both margins without indentation in the first paragraphs. Margins size will be $2.50 \mathrm{~cm}$. Where it could be necessary the incorporation of notes, they will be at the bottom of the page, consecutively numbered with typography Arial 10, simple line spacing and justified on both margins.

More detailed information is available on the website: http://www.um.es/cepoat/pantarei.

\section{Examination and assessment process}

The Journal will submit the papers to a first examination once received. If the paper follows the presentation guidelines, the subject agrees with the editorial line of this journal, and possess the scientific quality required, it will be sent to the advisory council for a first assessment. If not, the documents which clearly fail to complete the editorial line may be rejected straightaway in this first step.

The Advisory Council will indicate the originality, relevance, structure, writing, bibliography, etc. of the text to the journal; for this purpose, two outside experts will be designated to review the papers; these experts can be (or not) part of this Advisory Council. The selection of the experts will adjust to the subject and methodological characteristics of the paper. Name and affiliation of the author will be eliminated from the text for its review, in this way experts will act anonymously and confidentially.

The experts will fill out an assessment report which will focus on aspects such as formal characteristics, originality and novelty of the papers, relevance and results of the proposal, methodological quality and scientific validity.

Once the process is finished, the acceptance or not of the papers and its publication in the corresponding edition will be decided, as well as the modifications that may be done for its final publication. This notification will be sent by email within 6 months maximum. 


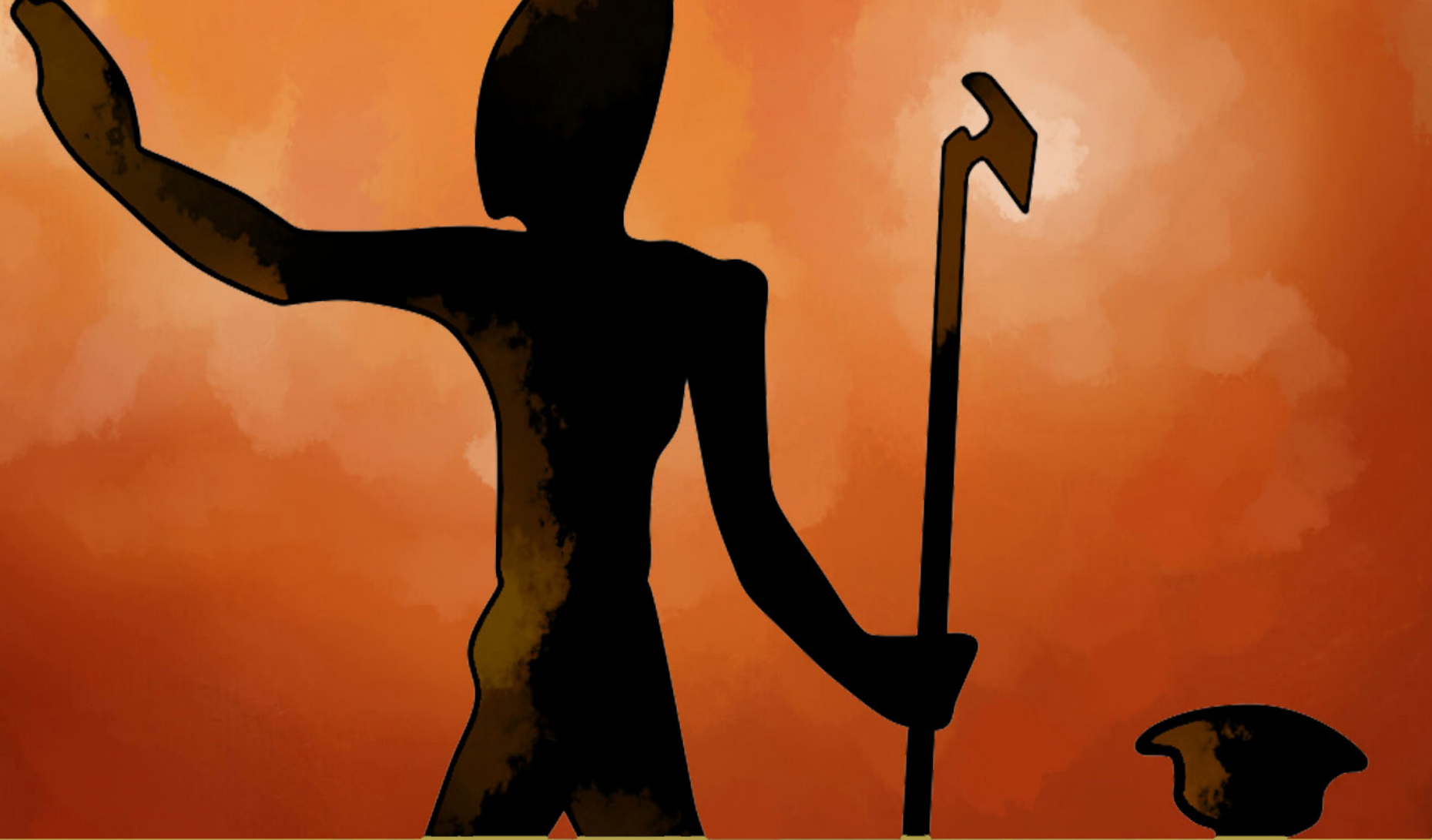

cepo t

UNIVERSIDAD DE MURCIA

centro de estudios del

próximo oriente y la

antigüedad tardía 